\title{
Estimation of Pathogenic Exposure Levels and Associated Baseline Bio-Risks in Edible Terrestrial Snails (Achachatina marginata) sold in Nigerian Markets
}

\author{
OKAFOR-ELENWO, EJ; *IMADE, OS
}

Department of Biological Sciences, College of Natural and Applied Sciences, Igbinedion University, Okada, Edo State, Nigeria. *Correspondent Author Email: imade.stanley@gmail.com; Tel: +2348125963557

\begin{abstract}
This research estimated the pathogenic exposure levels and associated baseline bio-risks in edible terrestrial snails (Achachatina marginata) sold in the Nigerian markets in an attempt to ascertain the probable contribution of contaminated snails to the burden of foodborne illnesses in Nigeria. Identification of bacterial pathogens in the edible snails was performed with phenotypic methods. Baseline probability (risk) of a case of illness caused by the identified pathogens was quantified with the United States FDA-iRisk version 4.0 stochastic software. Findings from this research revealed that there were gross contaminations of the meat surfaces of fresh snails (exposed foot of a snail) with bacterial indicators of hygiene [median viable (TAVC) and enterobacteria (TEC) counts $=7.23 \log _{10} \mathrm{CFU} / \mathrm{g}$ and $5.07 \log _{10} \mathrm{CFU} / \mathrm{g}$ respectively] and food safety [median presumptive Staphylococci (TSC) count $=4.71 \log _{10} \mathrm{CFU} / \mathrm{g}$ ]. The unsafe profile of the meat surface was further confirmed by the presence of high concentration (exposure level) of coagulase-positive Staphylococci pathogen [median concentration $=4.17 \log _{10} \mathrm{CFU}$ ]. Unlike the meat surface, concentrations of haemolytic (group B) Enterococci pathogen isolated from the viscera of snails were insignificant [median concentration of pathogen $=0 \log _{10} \mathrm{CFU}$. Therefore, snail meat surfaces were the main sources of significant risks to potential consumers. This probable significant health consequence was further corroborated by a predicted significant baseline risk which indicated that in the absence of adequate microbial mitigation protocols, 1750 potential human consumers above the age of 3 years were most likely to fall ill per 10000 potential consumers. Thus, there is a need for increased advocacy to ameliorate the baseline risks associated with edible fresh snails sold in Nigerian markets or exported to other markets around the world.
\end{abstract}

\section{DOI: https://dx.doi.org/10.4314/jasem.v23i4.16}

Copyright: Copyright $\odot 2019$ Okafor-Elenwo and Imade. This is an open access article distributed under the Creative Commons Attribution License (CCL), which permits unrestricted use, distribution, and reproduction in any medium, provided the original work is properly cited.

Dates: Received: 27 February 2019; Revised: 29 March 2019; Accepted 09 April 2019

Keywords: Bio-risk, Coagulase-positive Staphylococci, Group B Enterococci, FDA-iRisk software.

Archachatina marginata and Achatina achatina, which belong to the phylum Mollusca and class Gastropoda, are the main species of edible terrestrial snails sold in the Nigerian markets (Nwuzo et al., 2016). These edible giant land snails are inhabitants of the rainforests in the southern regions of Nigeria as well as in the coastal regions of other West African countries. Other snail species such as Achatina fulica have also been found in the rainforests of East Africa and many regions around the world (Cardoso et al., 2012). The gut microbiota in edible land snails has been shown to perform useful functions such as digestion of complex polysaccharides and ultimate generation of energy for metabolic activities, synthesis of essential amino acids and vitamins, prevention of growth of pathogens and defence against some diseases (Bonnemain, 2005). However, this perceived usefulness is tainted by the probable presence of microbial pathogens on the snails due to their close contact with soil and their uncontrolled feeding pattern with filthy decomposing materials (Ugoh et al., 2013; Nwuzo et al., 2016; Paskiewicz et al., 2018). Thus, despite the therapeutic and nutritional usefulness of edible snails (Bonnemain, 2005), their involvement as vectors of pathogenic microorganisms (Zhang et al., 2009) that cause a wide variety of diseases in humans calls for concern. In order to systematically address the potential (baseline) burden that may result from the impact of pathogen-contaminated snails, quantitative tools (Palisade Corporation, 2010; FDA/CFSAN/JIFSAN/RSI, 2017) that can predict the potential risks of illness due to these pathogens become immensely relevant. The baseline burden is often used to refer to a measure of the health impact that is associated with contaminated foods which had not been subjected to any form of risk mitigations such as thermal processing or chemical disinfection. The risk assessment is often performed with the protocols stipulated by the Codex Committee on Food Hygiene Principles and Guidelines for the Conduct of Microbiological Risk Assessment (Codex Alimentarius Commission, 1999) which include hazard identification, hazard characterization, exposure assessment and risk characterization. Since foodborne illnesses still account for over 420,000 deaths in the world per annum (WHO, 2017) and because over $17 \%$ of the costs of illnesses in Nigeria are spent on foodborne illnesses, the present study

*Correspondent Author Email: imade.stanley@gmail.com; Tel: +2348125963557 
estimated the pathogenic exposure levels and associated baseline bio-risks in edible terrestrial snails (Achachatina marginata) sold in the Nigerian markets in an attempt to ascertain the probable contribution of contaminated snails to the burden of foodborne illnesses in Nigeria.

\section{MATERIALS AND METHODS}

Study design: Four markets in four different localities in Nigeria were sampled. Thirty snail samples were purchased from different retailers in each of the markets and were then transported to the laboratory for analyses. Cumulatively, a total of 120 snails were examined in this study. Bacterial concentrations and prevalence variables were measured in these samples and the discrete concentration datasets were subsequently transformed into continuous variables. Randomization was performed with the iterative Wei's Urn randomization technique (Rosenberger and Lachin, 2002).Total aerobic viable counts (TAVC), total enterobacteria counts (TEC), total presumptive Staphylococci counts (TSC), and the concentrations of isolated pathogens were the main treatments that were examined. Parametric or non-parametric one-way (single factor) analysis of variance was performed on treatment variables based on the outcomes of normality and homoscedasticity tests. Normality of the datasets was performed with Shapiro-Wilk test and homoscedasticity of treatment groups performed with Levene test of homogeneity. The baseline risk of a case of illness associated with the snails was appropriately quantified with the United States FDA-iRisk version 4.0 stochastic software.

Preparation of snail specimens for microbial analyses: Each snail was measured with a digital weighing balance (G\&G GmbH, Germany) and the value was recorded. The outer shells of the snails were initially rinsed with distilled water and subsequently disinfected using cotton wool moistened in $70 \%$ alcohol. Each snail was then placed on a sterile tray and a sterile rod used to create perforations from where the whole meat consisting of the foot (herein referred to as the meat surface) and the viscera were collected for analyses.

Bacterial isolation and enumeration: Isolation of the bacteria in the viscera and on the surface of the snails was performed by spread-plating method (Public Health England, 2014). For the quantitative isolation of bacteria on the surface and in the viscera of each of the snails, $25 \mathrm{~g}$ portions aseptically excised from either the viscera or foot of the snail were homogenized in $225 \mathrm{ml} 1.5 \% \mathrm{~W} / \mathrm{V}$ sterile peptone water diluents to obtain an initial $10^{-1}$ dilution from where serial dilutions up to $10^{-5}$ were derived. One hundred microliters of each diluted suspension were subsequently spread on duplicate agar plates. All the agar plates were then incubated at $35^{\circ} \mathrm{C}$ for 18 to 24 hours. After incubation, distinct colonies seen in the plates were then enumerated and counts on nutrient agar plates, crystal violet red bile agar plates and mannitol salt agar plates were respectively used to deduce total aerobic viable counts $(T A V C)$, total enterobacteria counts (TEC) and total presumptive Staphylococci counts (TSC).

Genus-level identification: Ten distinct bacterial colonies were selected from the nutrient agar plate based on their colonial characteristics, and phenotypic identification was performed according to standard methods (Barrow and Feltham, 2003).

Estimation of the exposure levels (initial concentration and prevalence) of bacterial pathogens: The concentration of a bacterial pathogen in a snail sample was deduced from the prevalence of the bacterial pathogen as expressed in equations 1 and 2. Prevalence $\left(P_{s}\right)$ of contaminated snail sample(s) in the batch of snail samples examined in this study was calculated with equation 3 .

$$
C_{p}=P_{p} \times T A V C
$$

Where: $C_{p}$ is the concentration of a bacterial pathogen in a snail sample; TAVC represents the overall concentration of bacteria in a snail sample

$P_{p}=\frac{N_{s p}}{N_{t s p}}$

Where $P_{p}=$ prevalence of a bacterial pathogen in a snail sample; $N s p=$ number of specific bacterial pathogen on the nutrient agar plate; and Ntsp = total number of bacterial colonies that were examined on the nutrient agar plate

$P_{s}=\frac{N_{S s}}{N_{t s s}}$

Where $P_{s}=$ prevalence of contaminated snail sample; Nss = number of snail sample contaminated with the bacterial pathogen; and Ntss = total number of snail samples examined

Stochastic quantification of the concentration and prevalence of pathogens: Stochastic quantification of concentration and prevalence of a pathogen was performed with the FDA-iRisk software, version 4.0 (FDA/CFSAN/JIFSAN/RSI, 2017) based on the initial or original datasets obtained from the microbial analysis. The initial concentration of pathogen was 
derived from a unit mass of $25 \mathrm{~g}$ (the mass of snail meat used for experimental investigations). The stochastically-derived concentration values were subsequently inputted into a series of other calculations which were used to ultimately predict the baseline risks associated with snails sold in the Nigerian markets.

Estimation of the available and ingested dose of the consumption model: The available dose predicted the extent of contamination of the fresh snail meat with bacterial pathogens, and by inference, a measure of the degree of health risk that humans were potentially exposed to if appropriate intervention protocols (for example, adequate thermal intervention) were not performed prior to consumption of snail meat. The available dose referred to the estimated total amount of a pathogen in a proposed serving of a snail meat that had not been cooked. It is mathematically represented as follows:

$$
D_{a}=C_{a} \times M_{a}
$$

$D_{a}$ is the available dose of the pathogen in the uncooked snail meat (expressed in $\mathrm{CFU}$ ); $C_{a}$ is the stochastically-derived concentration of pathogen in the uncooked snail meat (expressed in $\mathrm{CFU} / \mathrm{g}$ ); $M_{a}$ is the amount of uncooked snail meat (expressed in $\mathrm{g}$ ) which if eventually cooked will be consumed at one eating occasion (serving size)

Conversely, ingested dose referred to the estimated residual amount of a pathogen in a serving of cooked snail meat consumed by a human. It is also mathematically represented by:

$$
D_{i}=C_{i} \times M_{i}
$$

$D_{i}$ is the dose of the pathogen in the cooked snail meat (expressed in $\mathrm{CFU}$ ); $C_{i}$ is the stochastically-derived concentration of pathogen in the cooked snail meat (expressed in $\mathrm{CFU} / \mathrm{g}$ ); $M_{i}$ is the serving size (expressed in $\mathrm{g}$ ) consumed at a single eating occasion

Since the serving size used to deduce the available and ingested dose is a fixed parameter, $M_{a}=M_{i}$. A serving size of $55 \mathrm{~g}$ that is often recommended for a one-time consumption in the population group of humans above 3 years of age (FDA, 2018) was inputted into the FDAiRisk modelling tool. Since the serving size was different from the previous unit mass (25 g unit size employed for experimental analysis) used in process modelling, the FDA-iRisk software was used to implement a 'pooling process type' to account for an increase in the new unit size (serving size).
Consumption model description: Since snail meat obtained from the Nigerian markets were only consumed after some form of thermal intervention such as cooking; this research, in an attempt to use available dose of pathogen in the fresh uncooked snail meat to evaluate the potential adverse effects (baseline risks) associated with snails sold in the Nigerian markets, adopted a consumption model whose logic assumed a scenario in which the ingested dose of pathogen in the cooked snail meat at the time of consumption equalled the available dose that was estimated in the fresh uncooked snail meat.

Dose-response modelling: The dose-response model predicted the percentage of the population in which an adverse effect (illness) may occur upon consumption of a contaminated serving of snail meat containing a specific dose of the pathogen (in this research, the specific ingested dose $=$ available dose) . Monte Carlo simulation of an empirical dose data, derived from experts' elicitation (Health Protection Agency, 2009) and inputted as $r$ (the probability that a single ingested pathogen was able to survive and initiate illness), was performed with the FDA-iRisk version 4.0 software to generate a dose-response model which was presented in the form of an exponential probability distribution. Each of the simulated doses generated by the FDAiRisk software was separately interpolated on the doseresponse curve to obtain the probability of response (potential adverse effect) for each of the iterations.

Estimation of the baseline probability (risk) of illness: The estimated mean probability (baseline risk) of illness inferred the degree of health risk that humans were exposed to if appropriate intervention protocols were not performed prior to consumption of the fresh snail meat. The mean probability of illness per serving was calculated across all the iterations simulated with the FDA-iRisk software as follows:

$$
P_{\ell h}=E\left[P\left(\varepsilon_{h} / A D_{\ell h}\right) \times P\left(\gamma_{h} / \varepsilon_{h}\right) \times P_{i}\right]
$$

Where $P_{f, h}$ is the mean probability (baseline risk) of illness;

$P\left(\varepsilon_{h} / A D_{f, h}\right)$ is the probability of response provided by interpolation from the dose-response model specified for hazard $(h)$ given ingested dose $\left(A D_{f, h}\right) ; P\left(\gamma_{h} / \varepsilon_{h}\right)$ is the probability of illness given response $\varepsilon_{h}$ occurred, if $\varepsilon_{h}$ is an end point other than frank illness; $P_{s}$ (probability of exposure) is the median prevalence of contaminated units of snail meat; $E$ denotes the expectation of the median values in the brackets, as computed from the mean of the iterations within a Monte Carlo simulation 


\section{RESULTS AND DISCUSSION}

Phenotypic characterization of bacteria isolated from the meat surface and viscera of snail: The results of phenotypic tests performed on bacterial isolates obtained from the surface and viscera of fresh snail meat agreed with expected standard results for these isolates (Barrow and Feltham, 2002). The bacteria that were isolated from meat viscera of snails were confirmed as Enterobacter species, Bacillus species, as well as haemolytic (group B) and non-haemolytic (group D) Enterococcus species. For the meat surface of snails, the isolated bacteria were confirmed as Bacillus species, Enterobacter species, coagulasepositive Staphylococcus species and coagulasenegative Staphylococcus species.

Extents of contamination with bacterial indicators of hygiene and food-safety: Concentration of bacterial indicators of hygiene and food-safety are presented in
Table 1. Since the concentration datasets were nonnormally distributed $(\mathrm{P}<0.05)$, the normality tests indicated that median concentrations were the most appropriate measure of central tendency. The median TAVC for the meat surface and viscera was respectively reported as $7.23 \log _{10} \mathrm{CFU} / \mathrm{g}$ and 3.90 $\log _{10} \mathrm{CFU} / \mathrm{g}$. For the median TCC values of meat surface and viscera, $5.07 \log _{10} \mathrm{CFU} / \mathrm{g}$ and $3.71 \log _{10}$ $\mathrm{CFU} / \mathrm{g}$ were reported. Median TSC was reported as $4.71 \log _{10} \mathrm{CFU} / \mathrm{g}$ for the meat surface. For the viscera samples, no Staphylococci species were isolated. The ANOVA, which was performed with the KruskalWallis tests using the chi-squared approximations, revealed that there was a significant difference $(\mathrm{P}<$ $0.05)$ in the median TAVC of the meat surface. A similar trend of significant difference in the median TCC and TSC of the meat surface was also observed. However, in the viscera of the snails, there were no significant differences $(\mathrm{P}>0.05)$ in TAVC datasets as well as in the TCC datasets.

Table 1: Concentrations of bacterial indicators of hygiene and food-safety in snail meat.

\begin{tabular}{|c|c|c|c|c|c|c|c|c|c|c|c|c|}
\hline \multirow{4}{*}{ Bacterial counts } & \multicolumn{12}{|c|}{ Bactenid load } \\
\hline & \multicolumn{6}{|c|}{$\begin{array}{c}\text { Meat surface } \\
(\mathrm{N}=120) \\
\left(\log _{10} \mathrm{CFU} / 8\right)\end{array}$} & \multicolumn{6}{|c|}{$\begin{array}{c}\text { Meat viscen } \\
(\mathrm{N}=120) \\
\left(\log _{10} \mathrm{CFU} / 8\right)\end{array}$} \\
\hline & Mean & Median & $\begin{array}{l}95 \% \mathrm{CI} \text { of } \\
\text { median }\end{array}$ & $\begin{array}{l}\text { Nor. } \\
{[y=} \\
0.05]\end{array}$ & $\begin{array}{l}\text { Hom. } \\
{[y=} \\
0.05]\end{array}$ & $\begin{array}{l}\text { ANOVA } \\
{[y=0.05]}\end{array}$ & Mean & Medizn & $\begin{array}{l}95 \% \mathrm{Cl} \text { of } \\
\text { median }\end{array}$ & $\begin{array}{l}\text { Nor. } \\
{[y=} \\
0.05]\end{array}$ & $\begin{array}{l}\text { Hom. } \\
{[y=} \\
0.05]\end{array}$ & $\begin{array}{l}\text { ANOVA } \\
{[y=0.05]}\end{array}$ \\
\hline & \multicolumn{6}{|c|}{ P-values } & & & & \multicolumn{3}{|c|}{ P-values } \\
\hline Total viable counts (TAVC) & 6.79 & 7.23 & $7.18-7.24$ & 0.00 & 0.00 & 20.00 & 3.88 & 3.90 & $3.84-3.94$ & 0.00 & 0.00 & 50.24 \\
\hline Total enterobieteri2 counts (IEC) & 5.56 & 5.07 & $5.00-5.70$ & 0.00 & 0.00 & $x_{0.00}$ & 3.67 & 3.71 & $3.62-3.76$ & 0.04 & 0.00 & $x_{0.28}$ \\
\hline Total Staphigiacocci counts (TSC) & 4.73 & 4.71 & $4.69-4.75$ & 0.01 & 0.00 & $x_{0.02}$ & . & . & . & - & . & - \\
\hline
\end{tabular}

$N$ : the total number of snail samples examined. CI: the confidence interval. Nor: normality of datasets; Hom: homoscedasticity of datasets. $\gamma$ indicates the probable margin of error. P-values: probability values. Superscripts $K$ indicate that one-way analysis of variance (ANOVA) was performed with Kruskal-Wallis tests of medians using the chi-squared approximation.

Findings from this research revealed that the meat surfaces of snails sold in the Nigerian markets had high bacterial load as indicated by the median TAVC, TEC and TSC (Table 1). In the absence of appropriate bacterial mitigation protocols, the fresh snail meat surfaces had bacterial concentrations that exceeded standard bacteriological limits (TAVC $<3 \log _{10}$ $\mathrm{CFU} / \mathrm{g} ; \mathrm{TEC}<2 \log _{10} \mathrm{CFU} / \mathrm{g} ; \mathrm{TSC}<1.3 \log _{10} \mathrm{CFU} / \mathrm{g}$ ) required for foods that were cooked immediately prior to consumption [ready-to-eat foods] (Health Protection Agency, 2009; Center for Food Safety Hong Kong, 2014). Adagbada et al. (2011) and Akpomie (2013) who worked with snails collected from the Nigerian environments also reported high bacterial load in the snail meats.

The results of this research were also in accordance with the findings of Paskiewicz et al. (2016) who worked with snail samples obtained from Poland in the
European environments. The findings of Paskiewicz et al. (2016) revealed that total viable counts and enterobacteria counts were $\leq 6.6 \log _{10} \mathrm{CFU} / \mathrm{g}$ and $\leq 4.8$ $\log _{10} \mathrm{CFU} / \mathrm{g}$ respectively. Since snails sold in the Nigerian markets are largely sourced from their natural habitats in the wild and because their feeding patterns are associated with filthy materials, these factors may account for the gross contamination levels seen in snails; as corroborated by the unsatisfactory bacterial indicators of hygiene and food-safety (Table 1).

Extents of contamination with bacterial pathogens: The extents of contamination with specific bacterial hazards in snail meat are reported in Table 2. The datasets of the initial concentrations of coagulasepositive Staphylococci and haemolytic (group B) Enterococci were non-normally distributed as indicated by the normality tests $(\mathrm{P}<0.05)$ and corroborated by the strong deviations from the mean 
concentrations. Thus, the median concentrations were the preferred measure of central tendency which most appropriately described the central location of the concentration variables. The central location of the prevalence variables were also aptly described by the median prevalence. As indicated by the ANOVA, the median concentrations of coagulase-positive Staphylococci on the meat surface were not significantly different $(\mathrm{P}>0.05)$. There was also no significant difference $(\mathrm{P}>0.05)$ in the median concentrations of haemolytic (group B) Enterococci in the viscera of snails

Table 2:Statistical variables of bacterial pathogens inputted into the FDA-iRisk software to stochastically quantify the exposure parameters.

\begin{tabular}{|c|c|c|c|c|}
\hline \multirow[b]{3}{*}{ Statistical parameters } & \multicolumn{4}{|c|}{ Specific hazards isolated from snail meat } \\
\hline & \multicolumn{2}{|c|}{$\begin{array}{l}\text { Coagulase-positive Staphylococci } \\
\text { isolated from the meat surface } \\
(N=120)\end{array}$} & \multicolumn{2}{|c|}{$\begin{array}{c}\text { Group B Enterococc } i \text { isolated } \\
\text { from the viscera } \\
(N=120)\end{array}$} \\
\hline & $\begin{array}{c}\text { Initial } \\
\text { prevalence of } \\
\text { contaminated } \\
\text { snails } \\
(\times 100 \%) \\
\end{array}$ & \begin{tabular}{l}
\multicolumn{1}{c}{ Initial } \\
concentration \\
$\left(\log _{10} \mathrm{CFU} / \mathrm{g}\right)$
\end{tabular} & $\begin{array}{c}\text { Initial } \\
\text { prevalence of } \\
\text { contaminated } \\
\text { snails } \\
(\times 100 \%) \\
\end{array}$ & $\begin{array}{c}\text { Initial } \\
\text { concentration } \\
\left(\log _{10} \text { CFU/g) }\right.\end{array}$ \\
\hline Mean & 0.720 & 3.040 & 0.180 & 0.500 \\
\hline Median & 1.000 & 4.170 & 0.000 & 0.000 \\
\hline Standard deviation & 0.450 & 1.930 & 0.390 & 1.060 \\
\hline Minimum & 0.000 & 0.000 & 0.000 & 0.000 \\
\hline Maximum & 1.000 & $4 . \$ 10$ & 1.000 & 3.100 \\
\hline Alpha $(\alpha)$ & 0.005 & 0.005 & 0.000 & 0.000 \\
\hline $\operatorname{Beta}(\beta)$ & 0.002 & 0.002 & 0.000 & 0.000 \\
\hline $95 \% \mathrm{CI}$ of mean & $0.600-0.830$ & $2.540-3.530$ & $0.080-0.280$ & $0.220-0.770$ \\
\hline $95 \%$ CI of median & $1.000-1.000$ & $4.140-4.330$ & $0.000-0.000$ & $0.000-0.000$ \\
\hline Normality $(\gamma=0.05)$ & * & 0.000 & $*$ & 0.000 \\
\hline Hom. $(\gamma=0.05)$ & * & 0.520 & $*$ & 0.280 \\
\hline ANOVA $(\because=0.05)$ & - & $\kappa_{0.110}$ & $*$ & $x_{0.140}$ \\
\hline
\end{tabular}

$N$ : the total number of snail samples examined.CI is the confidence interval. Hom: homoscedasticity of datasets. $\gamma$ indicates the probable margin of error, while P-values were the probability values of datasets. Superscripts $k$ indicates that one-way analysis of variance (ANOVA) was performed with Kruskal-Wallis tests of medians using the chi-squared approximation. (*) indicate that the statistical parameters were not required. The amount of contamination (A) added to the snail meat is mathematically expressed in equation 7

$A=B \times C$

Where $A=\log _{10} \mathrm{CFU} ; B=\log _{10} \mathrm{CFU} / \mathrm{g}$ and $C=\mathrm{Unit}$ mass used for experimental analysis $(25 \mathrm{~g})$

$$
\begin{aligned}
& \alpha=\left(\frac{1-\mu}{\sigma^{2}}-\frac{1}{\mu}\right) \mu^{2} \\
& \beta=\alpha\left(\frac{1}{\mu}-1\right) \\
& a: \text { alpha; } \beta \text { : beta; } \mu \text { : mean; } \sigma \text { : variance }
\end{aligned}
$$

Stochastic quantification of the extents of contamination with bacterial pathogens: Monte Carlo simulations used to quantify the uncertainty in the prevalence of coagulase-positive Staphylococci was performed by Latin Hypercube sampling of the beta probability distribution [Beta (alpha, beta)] of the initial prevalence datasets (Figure 1). Quantification of the variability in concentration parameter was based on the outcome of normality tests performed on the initial concentration datasets of coagulase-positive Staphylococci. Since the initial concentration datasets of the coagulase-positive Staphylococci were nonnormally distributed $(\mathrm{P}<0.05)$, the Monte Carlo simulations employed a probability distribution [BetaGeneral (Alpha, Beta, Lower bound, Upper bound)] that aptly described the median concentrations of the coagulase-positive Staphylococci in the snail population to quantify the variability in the concentration of the coagulase-positive Staphylococci (Figure 1). No graphical presentations of the uncertainty and variability in the datasets of hemolytic (group B) Enterococci were presented because the alpha and beta variables were reported as zero, and also because the confidence interval of the median concentration was reported as $0.00 \log _{10} \mathrm{CFU} / \mathrm{g}$. The presence of high concentration of coagulase-positive Staphylococci pathogen (Table 2, Figure 1) in the meat surfaces of snails sold in the Nigerian markets, as well as the presence of Listeria monocytogenes in the meat surfaces of snails obtained from Poland as indicated in the study of Paskiewicz et al. (2018), further substantiated the gross pathogenic contamination levels seen in snails. Thus, adequate precautions must be adhered to during handling of fresh snails purchased from the Nigerian markets, including other markets around the world; and sufficient thermal treatments of the snail meats are also required prior to consumption. The probability distribution charts were implemented with the FDA-iRisk software, version 4.0. (A) Represents the uncertainty distribution of the prevalence parameter. $(\boldsymbol{B})$ Represents the variability 
distribution of the concentration parameter. The blue line represents the cumulative density function (CDF), while the yellow line represents the probability density function (PDF).

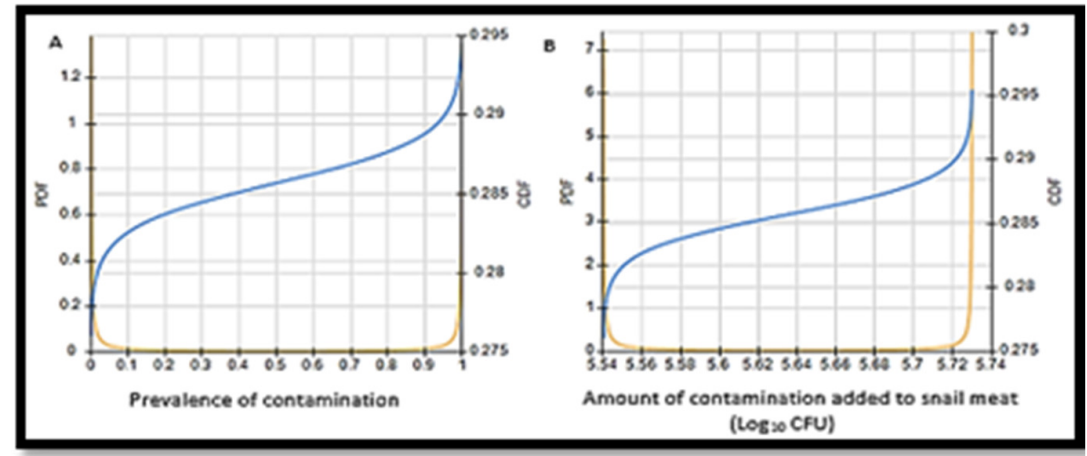

Fig 1: Probability distribution curves used to stochastically quantify the uncertainty in the prevalence and variability in the concentration of coagulase-positive Staphylococci in the snail meat population.

Serving size inputted into the FDA-iRisk software: The serving size of snail meat per eating occasion in the population group of humans above 3 years of age is reported is Table 3.

Dose-response model: The dose-response model due to consumption of coagulase-positive Staphylococcicontaminated snail meat in the examined population group is shown in Figure 2. The simulated median doses generated by the FDA-iRisk software were separately interpolated on the dose-response curve to obtain their respective probabilities of response.

Estimation of the probability (baseline risk) of illness: The baseline risk of a case of illness due to the 'available dose' of bacterial pathogens harboured in fresh snails sold in the Nigerian markets was based on the expectation of median doses and prevalence. Thus, estimations generated by the FDA-iRisk software were obtained with $50 \%$ uncertainty. Contaminations due to coagulase-positive Staphylococci appeared to cause the highest potential adverse effects upon consumption when compared to contaminations due to haemolytic (group B) Enterococci. In the absence of adequate microbial mitigation protocols prior to consumption of snail meat sold in the Nigerian markets, the presence of coagulase-positive Staphylococci appeared to pose significant risk to potential consumers since 1750 potential consumers above the age of 3 years were most likely to fall ill per 10000 potential consumers in this population group; assuming that illness results from a single eating occasion (acute illness). However, the reverse was the case with the presence of haemolytic (group B) Enterococci since potential consumers were most likely not to fall ill even in the absence of adequate microbial mitigation protocols. The baseline risk of illness was quantified with the FDA-iRisk version 4.0 stochastic tools using inputs (Table 2, Figure 1) obtained from surveillance of the markets where snails are sold in Nigeria and from experts' elicitations (Table 3, Figure 2). This research revealed that the snail meat surface was the main source of significant risks to potential consumers. The pathogen that was mostly implicated was the cogulasepositive Staphylococci with predicted baseline risk of foodborne illness per human above 3 years of age estimated at $1.75 \times 10^{-1}$. This risk estimate indicated that snails may probably be a significant contributor to the burden of foodborne illness in Nigeria. This may be the first time in Nigeria that the baseline bio-risks associated with fresh snails sold in the Nigerian markets was attempted as there were no published data from other Nigerian authors to compare our findings.

Table 3: Statistical parameters of the consumption and dose-response models inputted into the FDA-iRisk software

\begin{tabular}{|c|c|c|c|}
\hline Specific hazards & Population group examined & Sening size (g) & $r$ \\
\hline Coagulase-positive Staphlococci & Humans abore the age of 3 years & 55 & $1.82 \times 10^{-7}$ \\
\hline
\end{tabular}

( $r$ ) represents the probability that one pathogen will survive and cause illness, and is mathematically defined as the ratio of infectious dose. Serving size of snail meat was calculated based on the recommendation of the United States Food and Drug Administration (FDA, 2018). Infectious concentration of the coagulase-positive Staphylococci $=10^{5} \mathrm{CFU} / \mathrm{g}$ (Health Protection Agency, 2009).

The significant risks associated with coagulasepositive Staphylococci-contaminated snail meats in the
Nigerian snail chain are a pointer to the ease with which cross-contamination of this pathogen could 
occur, especially as a result of improper handling by humans who source for snails as well as in humans who sell or process the snails.

In the viscera of snails sold in the Nigerian markets, high bacterial load was also observed as indicated by the median TAVC and TEC (Table 2).

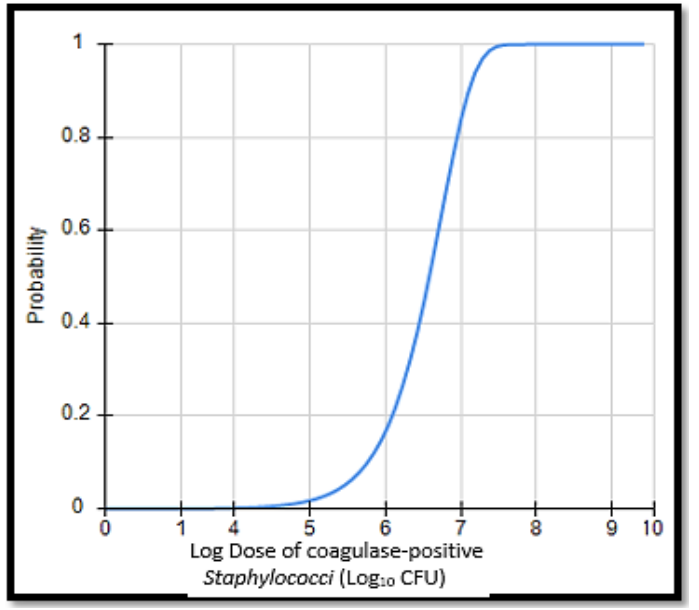

Fig 2: Dose-response curve of coagulase-positive Staphylococci in contaminated snail meat.

However, except for the insignificant concentration of haemolytic (group B) Enterococci pathogen as reported in Table 2, all the other bacteria obtained from the viscera that constitute the bacterial load appeared to be nonpathogenic normal flora of the snails' gut. The nonpathogenic normal flora seen in the snails' gut may not pose any detrimental effects to human consumers and could even constitute probiotics that might complement the gut microbiota of human consumers. The high concentrations of nonpathogenic normal flora in the snails' gut may also corroborate the suggestions alluded to by several authors (Bonnemain, 2005) that the guts of snails contained an intriguing microbiota that specialized in the rapid hydrolysis and fermentation of plant biomass and food materials with extraordinary efficiency.

Conclusion: While the viscera of snails contained microbiota that may be useful to humans, the meat surfaces were found to be unsatisfactorily contaminated with the bacterial indicator of foodsafety which negatively impacted the snail meat. The meat surfaces also appeared to constitute reservoirs of coagulase-positive Staphylococci pathogens. Thus, there is a need for increased advocacy by relevant government agencies as it relates to control measures such as proper personal hygiene upon contact with snails and also sufficient thermal treatment of the snail meat prior to consumption.

\section{REFERENCES}

Adagbada, AO; Orok, AB; Adesida, SA (2011). The prevalence and antibiotic susceptibility pattern of entero-pathogens isolated from land snails commonly eaten in Cross River and Akwa Ibom States, South-southern Nigeria. Asian J. Pharm. Health Sci.1: 123 - 127.

Akpomie, OO (2013). Assessment of health implication associated with snails and snail farm soils in Warri and Sapele, Delta State, Nigeria. Nig. J. Sci. Environ. 12:50 - 56.

Barrow, GI; Feltham, RKA (2003). Cowan and Steel's Manual for the identification of Medical Bacteria ( $3^{\text {rd }}$ ed.), Cambridge University Press, United Kingdom, p. $129-149$.

Bonnemain, B (2005). Helix and drugs: snails for western health care from antiquity to the present. Evid. Based. Complement. Alternat. Med.2: 25 28.

Cardoso, AM; Cavalcante, JJV; Vieira, RP; Lima, JL; Grieco, MAB; Clementino, MM (2012). Gut bacterial communities in the giant land snail Achatina fulica and their modification by sugarcane-based diet. PLoS One 7: e33440.

Centre for Food Safety (2014). Microbiological quality guidelines for food (for ready-to-eat-food in general and specific food items). Hong Kong: Centre for Food Safety, p. 38.

Codex Alimentarius Commission (1999). Principles and guidelines for the conduct of microbiological risk assessment. CAC/GL-30, Rome: Food and Agricultural Organization of the United Nations, [Accessed $17 \quad$ March 2019] http://www.fao.org/3/y1579e/y1579e05.htm.

Food and Drug Administration, Center for Food Safety and Applied Nutrition, Joint Institute for Food Safety and Applied Nutrition, and Risk Sciences International (FDA/CFSAN/JIFSAN/RSI)(2017). FDA-iRISK® version 4.0 Technical Document. College Park, Maryland, United States, p. 78.

Food and Drug Administration (FDA) (2018). Food for Human Consumption. Code of Federal Regulations Title 21 vol. 2, United States, [Accessed $17 \quad$ March 2019] http://www.accessdata.fda.gov.

Health Protection Agency (2009). Guidelines for assessing the microbiological safety of ready-to- 
eat foods. London: Health Protection Agency, p. $6-11$.

Nwuzo, AC; Iroha, IR; Moses, IB; Ugbo, EN; Agumah, NB; Orji, J (2016). Isolation and characterization of bacterial species associated with edible snails (Achatina achatina) sold in major markets within Abakaliki metropolis. Biolife 4: 494 - 497.

Palisade Corporation (2010). Guide to Risk Analysis and Simulation Add-In (@Risk-Version 5.7) for Microsoft ${ }^{\circledR}$ Excel. United States: New York, p. 693.

Paszkiewicz, W; Kozyra, I; Bigoraj, E; Ziomek, M; Rzezutka, A. (2016). A molecular survey of farmed and edible snails for the presence of human enteric viruses: Tracking of the possible environmental sources of microbial mollusc contamination. Food Control 69: 368 - 372.

Paszkiewicz, W; Szkucik, K; Ziomek, M; Gondek, M; Pyz-Lukasik, R (2018). Occurrence of Samonella spp. and Listeria spp. in snail meat. Med. Weter. 74: 110 - 113 .

Public Health England (2014). Preparation of Samples and Dilutions, Plating and Sub-culture: Microbiology Services, Food, Water and Environmental Microbiology Standard Method FNES26 (F2), Version 1. (1 ${ }^{\text {st }}$ ed.), London: Waterloo Road, p. 21.

Rosenberger, WF; Lachin, JM (2002). Randomization in Clinical Trials - Theory and Practice. John Wiley and Sons, p. 288.

Ugoh, SC; Ugbenyo, AJ (2013). Studies on the isolation of enteropathogens associated with the intestines of giant African land snails (Achatina and Archachatina) species sold in Gwagwalada, FCT, Abuja. Nigeria. Research 5: 56 - 59.

World Health Organization (WHO 2017). Fact sheets on food safety. Geneva: World Health Organization, [Accessed 17 March 2019] http://www.who.int/newsroom/factsheets/detail/food-safety 